\title{
Rock Physics Formula and RMS Stacking Velocity Calculation to Assist Acoustic Impedance Inversion that Constrain Well Data
}

\author{
Handoyo $^{1}$, Mochammad Puput Erlangga ${ }^{1}$, Fatkhan $^{2}$, Paul Young ${ }^{3}$ \\ ${ }^{1}$ Geophysical Engineering, Institut Teknologi Sumatera, South Lampung, Indonesia. \\ ${ }^{2}$ Geophysical Engineering, Institut Teknologi Bandung, West Java, Indonesia \\ ${ }^{3}$ TGS NOPEC Geophysical Company ASA, Perth, Australia
}

* Corresponding author : handoyo.geoph@tg.itera.ac.id

Tel.: +6285295400039

Received: Apr 29, 2020. ; Accepted: Jun 4, 2020

DOI: 10.25299 /jgeet.2020.5.2.3089

\begin{abstract}
This research ilustrate the generation of acoustic impedance inversion in the absence of well log using stacking velocity input in Salawati Basin, Papua, Indonesia using data obtained from seismic lines and stacking velocity section. Initial acoustic impedance models were first before the inversion process and were created by spreading the value of well log data to the all seismic CDP. The calculated acoustic impedance logs from standard sonic and density logs were used to build the initial model of acoustic impedance. First, the stacking velocities was first interpolated on a grid that has the same size as the seismic data using by means of Polynomial algorithm. This was closely followed by the conversion of the stacking velocities to interval velocities using Dix's equation. The matrix densities were estimated by simple rock physics approach i.e. Gardner's equation as a velocity function. The initial model of acoustic impedance was calculated by multiplying the densities section and interval velocities section. The resulting initial model of acoustic impedance was inverted to obtain the best of acoustic impedance section based on reflectivity.
\end{abstract}

Keywords: Acoustic Impedance, Rock Physics, Stacking Velocity, Wellog

\section{Introduction}

To conduct an acoustic-impedance inversion using bandlimited seismic data, the elastic parameters information must be given from the other data than the seismic reflectivity estimate. Well logs are commonly used for this purpose (Lindseth, 1979); however, stacking velocities can also be used to provide the low-frequency component (Oldenburg et al, 1984).

In this paper, an attempt was made to carry out seismic inversion using interval velocity model from stacking velocity due to non-availability of well $\log$ data. We also used the Gardner's relationship to calculate the density. Thus, we get the initial model of acoustic impedance section by multiplying the interval velocity and the density that resulted from Gardner relationship. This initial model was inverted to obtain the acoustic impedance volume based on the seismic reflectivity.

\section{Data and Method}

\subsection{Data}

Salawati Basin is a foreland basin trending East-West and located in the northern part of Indo-Australia Plate (Figure 1). This basin is bounded by deformation zone of Sorong Fault in the northernand western part. In the southern part, the basin is bounded by Misool-Onin High, while the eastern boundary is the Ayamaru Plateau. Salawati Basin records the stratigraphy and tectonic histories from Paleozoic until recent (Satyana, 2003).

Generally, the stratigraphy of Salawati Basin can be divided into two parts base on age, pre-Tertiary and Tertiary (Figure 2). The oldest stratigraphic sequence in Salawati Basin is metamorphosed continental bedrock of Kemum Formation with age of Silurian-Devonian. Mesozoic sediments (Tipuma and Kembelangan Group) were deposited only in the south because of uplifting or non-deposition in the nort (Satyana, 2003). There are three exploration wells in the western part of Salawati Island which that penetrated to Cretaceous granitic rocks intruding Paleozoic metamorphics (Situmeang, 2012).

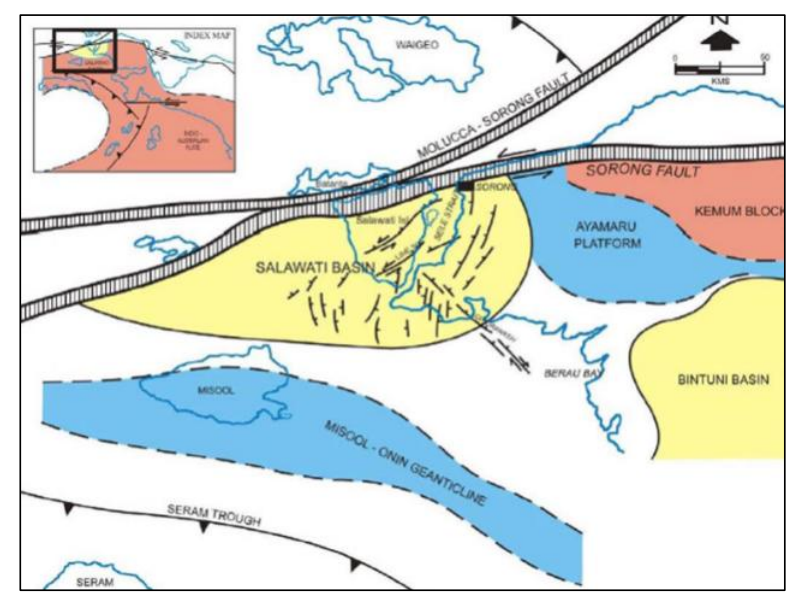

Fig1. Geologic setting of Salawati Basin south of Sorong Fault. Sorong Fault major control for geologic configuration of the basin (Satyana, 2003).

\subsection{Method}

Stacking velocities are generated during the processing of the seismic data in velocity analysis step. For this paper we used the Hussar data set as described in Lloyd and Margrave [2],[3]. The method of this study follow the steps: (1) Extract the stacking (RMS) velocity trace from stacking velocity section; (2) Make the selected stacking velocity trace as velocity log data; (3) Horizon picking and create the stacking (RMS) velocity model; (4) Convert the stacking (RMS) velocity section into interval velocity section; (5) Create the density section from interval velocity section using Gardner 
relationship; (6) Create the acoustic impedance section from interval velocity section and density section; (7) Make the Acoustic Impedance section as the initial model and then do the model based inversion.

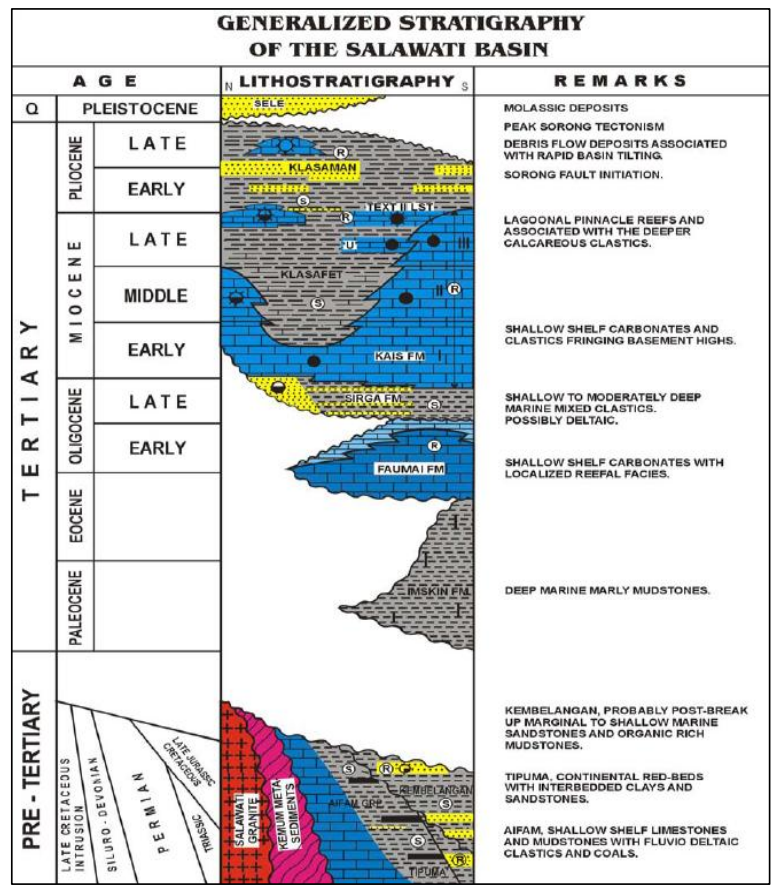

Fig 2. Regional stratigraphic setting of Salawati Basin. The stratigraphy of Salawati Basin can be divided intotwo major parts based on age pre-Tertiary and Tertiary (Satyana, 2003).

to convert the stacking velocities to interval velocities using the standard Dix interval velocity calculation (Margrave, 2002). The equation is shown below:

$$
v_{n}=\sqrt{\frac{V_{n}^{2} \tau_{n}-V_{n-1}^{2} \tau_{n-1}}{\tau_{n}-\tau_{n-1}}}
$$

After obtaining the interval velocity section from the stacking (RMS) velocity section, the densities can be calculated using the empirical rock physics relation between velocity and density relationship e.g. Gardner's equation from Mavko et al, 2009:

$$
\rho=310 V_{p}^{0.25}
$$

where $\rho$ are the density and Vint are the interval velocity. Then, the acoustic impedance is calculated by the following equation:

$$
A I=\rho V_{p}
$$

The material of this study consist of 2D line seismic data and stacking velocity from the field area, South Salawati Basin.

\section{Result and Discussion}

\subsection{Result}

The result of the extract stacking (RMS) velocity trace from stacking velocity section to make the synthetic log is as shown in Figure 3. The synthetic well was located in a position that have been preiously choosen. Then, the lithostratigraphic horizon of interest were interpreted in some area. The result of these process is shown in Figure 4. The horizon indicate the different lithology (physical properties) and the possibility of carbonate existence.

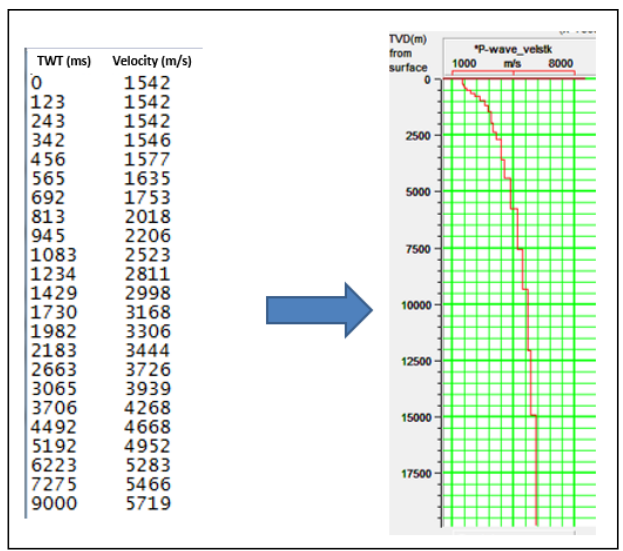

Fig 3. The result of syntetic log velocity extracted from stacking velocity section

After the horizons interpretation, the value of stacking (RMS) velocity from well to all seismic CDP trace was spread. The spreading of stacking (RMS) velocity value from well was guided by the seismic horizons. The RMS velocity section tend to be the low frequency model and the smoothing technique was applied to the section. The result of RMS velocity section is shown in Figure 5.

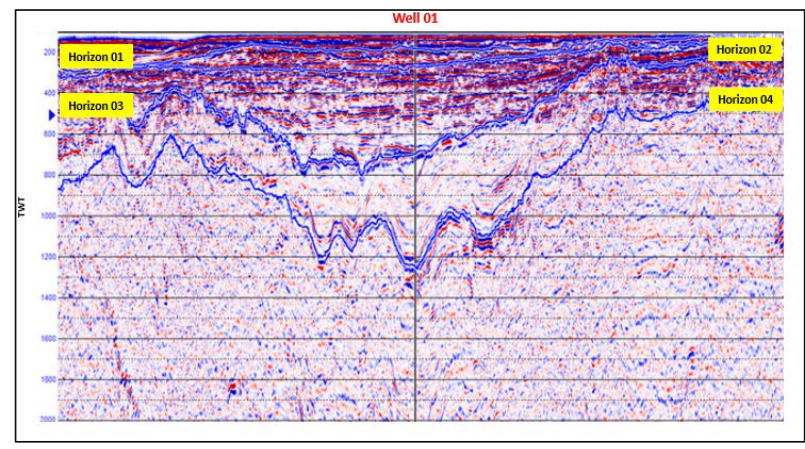

Fig 4. The horizon interpretation results and display of well location We propose four interest horizons.

After obtaining the RMS velocity section, the next step was the calculation of the interval velocity using equation 1 . The result of interval velocity section is shown in Figure 6 (a). Then, the acoustic impedance was calculated by equation 2 and 3 , and make it as an initial model of the acoustic impedance. The result of initial acoustic impedance model section shown in Figure 6 (b).

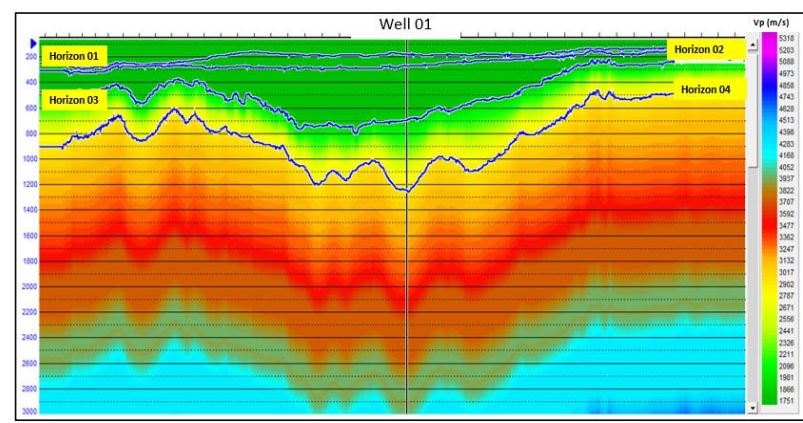

Fig 5. The result of RMS velocity section.

The final step was the acoustic impedance inversion using model based inversion technique. The inversion input was based on using the initial model of acoustic impedance as 
shown in figure 6 (b). The result of acoustic impedance inversion is shown in Figure 7.

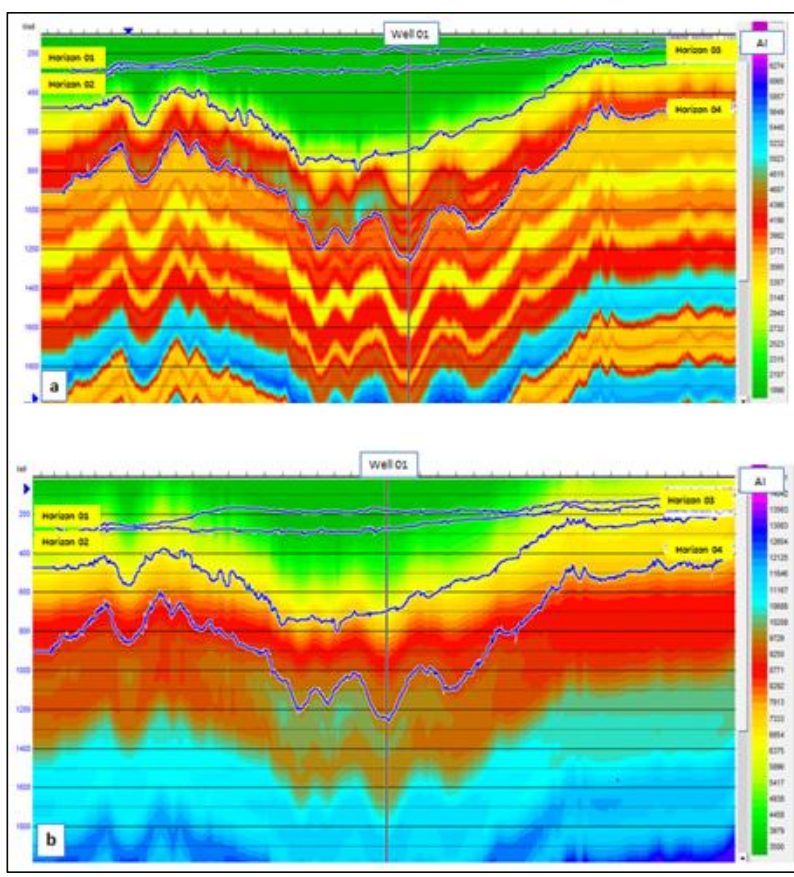

Fig 6. (a) The interval velocity section and (b) the initial model of acoustic impedance.

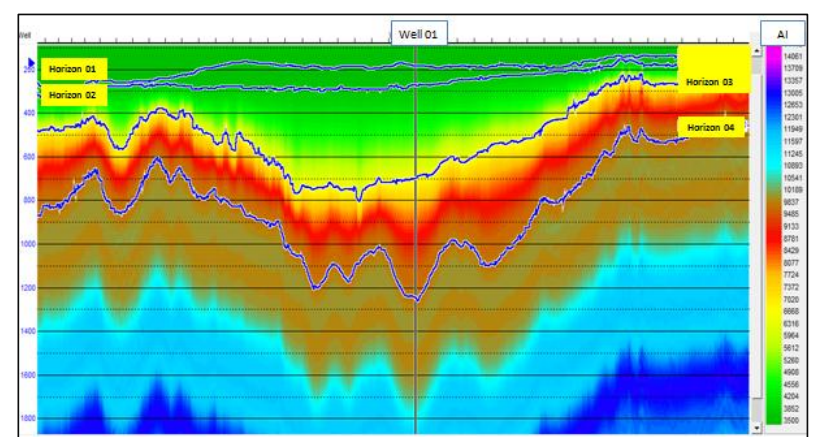

Fig 7. Inverted acoustic impedance.

\subsection{Discussion}

Because the inversion was mainly dependent on well data or accurate stacking velocities, picking them with the intent of using them for inversion helped the results greatly. In this study, they were very sparse laterally so picking more locations would help constrain lateral variation. Picking more structure samples vertically also helped constrain any anomalies, however making picks too close together created instabilities in the conversion to interval velocities.

In this study, we used a very simple way of calculating interval velocities. There are more advanced methods of calculating interval velocities and they should be investigated. Oldenburg et al. (1984) discussed using weighted least squares methods to produce a smooth variation. They also discussed using known interval velocities as controls when converting the stacking velocities to interval velocities.

\section{Conclusions}

This study conclude that it is possible to get a good acoustic impedance estimation using the stacking velocities and rock physics equation. However, when well log data is absent or the well position coordinate is so far to the seismic line, stacking velocities provide an interesting alternative. We can generate the initial model of acoustic impedance using interval velocity from stacking velocity and the density from velocity. The Dix's equation is able to convert the stacking velocity to the interval velocity and the Gardner relationship can convert the density from the interval velocity as well.

\section{Acknowledgements}

The authors are very grateful to Data courtesy of TGS for the permission publish this article.

\section{References}

Lindseth, R. O., 1979, Synthetic sonic logs - a process for stratigraphic interpretation: Geophysics, Vol. 44, No. 1.

Margrave, G. F., 2002, Methods of Seismic Data Processing Lecture Notes Geophysics 577: University of Calgary.

Mavko G., Mukerji T. and Dvorkin J. 2009. The Rock Physics Handbook: Tools for Seismic Analysis in Porous Media. Cambridge University Press.

Oldenburg, D. W., Levy, S. and Stinson, K., Root-mean-square velocities and recovery of the acoustic impedance. Geophysics, Vol. 49 No. 10. 1653-1663.

Situmeang, M., 2012, Karakteristik Reservoar Karbonat Menggunakan Inversi Sparse Spike di Lapangan "Panda" Formasi Kais Cekungan Salawati, Papua [unpublished]: Yogyakarta, Universitas Pembangunan Nasional "Veteran", 76p.

Satyana, A. H., 2003, Sorong Fault and Reversal of the Salawati Basin: Indonesian Petroleum Association Newsletter, Jakarta, March 2003.

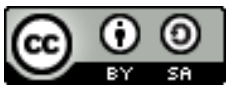

(C) 2020 Journal of Geoscience, Engineering, Environment and Technology. All rights reserved. This is an open access article distributed under the terms of the CC BY-SA License (http://creativecommons.org/licenses/by-sa/4.0/). 